DISEASE MARKERS, VOL. 11, 191-203 (1993)

\title{
ASSOCIATION OF THE HLA-A2, CW2, B27, S31, DR2 HAPLOTYPE WITH ANKYLOSING SPONDYLITIS. A POSSIBLE ROLE OF NON-B27 FACTORS IN THE DISEASE
}

\author{
GIORGIO LA NASA*, ALESSANDRO MATHIEU ${ }^{\dagger}$, MARINA MULARGIA*, CARLO CARCASSI*, \\ ADRIANA VACCA*, ANTONIO LEDDA*, LICINIO CONTU* \\ *The Department of Medical Genetics and the ${ }^{\dagger}$ Department of Rheumatology II of the Institute of \\ Clinical Medicine, University of Cagliari, Cagliari, Italy.
}

\section{SUMMARY}

With the aim of searching for HLA haplotypes and non-B27 allele frequency variations in Sardinian AS patients, HLA-A, B, Cw, DR, DQ and Bf, C4A and C4B typing and haplotype assignment was carried out in the families of $25 \mathrm{AS}$ patients and in 44 healthy individuals, all B27 heterozygotes. In the AS patients a significant increase of the A2, Cw2, B27, DR2, DQ1 haplotype was found. This depends only partially on the linkage disequilibrium existing in the Sardinian population between B27 and the other alleles of this haplotype, and rather seems to be due to a primary association of $\mathrm{Cw} 2$ and DR2 alleles with AS. Preliminary data seem to show that this haplotype bears the S31 complotype and the DRB1*1601 allele both in the AS patients and in the healthy controls. The pathogenetic implications of these findings are discussed.

KEY WORDS MHC antigens Spondylarthropathies HLA and disease

\section{INTRODUCTION}

Ankylosing Spondylitis (AS) is a disease with one of the highest and more constant degrees of association with an antigen of the HLA system (Tiwari and Terasaki, 1985). The frequency of the HLA-B27 antigen is in fact round 90\% among AS Caucasoid patients (Tiwari and Terasaki, 1985; Khan et al., 1980; Troug et al., 1975; Calin, 1982) and varies from 50 to $100 \%$ in the other ethnic groups studied (Khan et al., 1980; Calin, 1982). Nonetheless, most individuals bearing the B27 antigen do not develop AS.

In an attempt to explain the incomplete association between AS and B27, various hypotheses have been formulated, some of which suppose the coexistence of environmental factors (Calin and Elswood, 1989) and other associated genetic factors (Møller et al., 1982; Woodrow, 1985; Derhaag, 1990). In the HLA Class I region Mc.Daniel et al. have reported the presence of a DNA restriction fragment which can be inherited indifferently with both the $\mathrm{B} 27^{+}$and $\mathrm{B} 27^{-}$haplotypes and which seems to confer an extremely high relative risk for AS in $\mathrm{B} 27^{+}$subjects (McDaniel et al, 1987). This finding has not been confirmed by other authors (Durand and Taurog, 1987;

Correspondence to: Prof. Licinio Contu, Cattedra di Genetica Medica, Università di Cagliari, Via S. Giorgio, 12, 09124 Cagliari, Italy. 
Demazière et al., 1990) However, Robinson et al. have demonstrated that the HLA-B60 antigen is capable of enhancing the susceptibility to AS conferred by B27 (Robinson et al., 1989). Therefore it cannot be ruled out that other HLA genes borne by B27 positive or B27 negative haplotypes may be involved in AS susceptibility or play a supplementary role in increasing the risk of AS in B27 positive individuals. In this context it seemed interesting to search for these genetical factors in the Sardinian population because of its high genetic homogeneity (Piazza et al, 1985; Contu et al., 1992) and the strong B27 AS association already reported (Contu et al., 1977). A study was therefore carried out on the families of AS patients and of healthy individuals starting from B27 heterozygous probands, to search for eventual variations of the HLA allele frequencies on the $\mathrm{B} 27^{+}$and B27- haplotypes and/or of the haplotype segregation in the AS families.

\section{MATERIALS AND METHODS}

\section{Probands}

Our study started from 25 randomly selected unrelated AS patients, all HLA-B27 heterozygotes. The complete families including $30 \mathrm{~B} 27$ positive patients for a total of 134 individuals were studied. In four of these families there were 2 or more affected members and the first observed patient was chosen as the proband. Of the 25 probands, 21 were male and 4 were female, aged from 22 to 64 years (mean age 39 years). In 6 cases the proband was a parent and in 19 cases a sibling. The patients came from different island provinces and were of certain Sardinian origin. All of them fulfilled the New York criteria for definite AS (Calin, 1982) and presented typical symptoms and signs of the disease with advanced radiologic changes in the sacroiliac joints.

In each family the complete HLA haplotypes were determined and the probands were used for analysis.

\section{Control groups}

Two control groups were used. The first group included 45 unrelated healthy individuals, 32 males and 13 females, aged from 21 to 46 years (mean age 35 years). They were selected from the general population for having the HLA-B27 antigen and no personal/family AS or back pain history. In this group also all the family members were studied (191 individuals) and the HLA haplotypes determined. One of the 45 probands was excluded from the analysis for being B27 homozygous. The second group consisted of 220 randomly selected unrelated healthy individuals. The control groups came from the same provinces as the patients.

\section{HLA typing}

Patients, control groups and family members were typed for the currently recognized HLA antigens with mono-oligospecific sera according to a NIH standard two-stage microlymphocytotoxicity method. The number of HLA antigens tested were $16 \mathrm{~A}, 30 \mathrm{~B}$, $8 \mathrm{Cw}, 10 \mathrm{DR}$ and $3 \mathrm{DQ}$.

\section{Complement allotyping}

$\mathrm{C} 4 \mathrm{~A}$ and $\mathrm{C} 4 \mathrm{~B}$ allotypes were determined by immunofixation electrophoresis of neuraminidase-treated EDTA plasma as described in literature (Awdeh and Alper, 1980). Bf alleles were determined by immunofixation electrophoresis using a standard method (Alper et al, 1972). 


\section{Statistical analysis}

The HLA antigen frequencies observed were compared within the group of AS patients, the group of healthy $\mathrm{B} 27^{+}$individuals and the random control group. The expected frequencies of the B locus antigens in the patients and in the 44 healthy $\mathrm{B} 27^{+}$ controls were calculated on the allele frequencies of the B27 negative haplotypes and used for comparison with the random control group. The statistical significance of the differences was calculated using Fisher's exact "p" test and the relative risk (RR) by Haldane's method (Haldane, 1955). The significant "p" values were corrected according to the Bonferroni inequality method, considering each HLA locus separately (Tiwari and Terasaki, 1985). All the haplotypes in the AS patients and in the $\mathrm{B} 27^{+}$ healthy controls for a total of 138 haplotypes were defined. The haplotypes were assigned according to the family analysis using a standard method. When a blank allele could not be defined, it was considered as a different allele. The haplotype frequencies were calculated by direct counting.

\section{RESULTS}

The significant variations of the HLA antigen frequencies in the AS patients compared to the group of 220 healthy controls are reported in Table 1 . A positive association with the disease is shown for the HLA-A2, Cw2, DR2, DQ1 antigens and a negative association is shown for the A30, Cw5, DR3 and DQ2 antigens. No association was found for the B locus antigens (data not presented).

Most of these variations are also present when the AS patients are compared with the group of 44 B27 positive healthy controls (Table 2). In fact the frequencies of the A2, Cw2, DR2 and DQ1 antigens are significantly increased and that of the DR3 antigen significantly decreased in the group of patients. However, only the variations of A2, Cw2 and DR2 remain significant after correction for the number of antigens tested.

The comparisons between the antigen frequencies of the healthy $\mathrm{B} 27^{+}$probands and the random controls only revealed significant differences for the $\mathrm{Cw} 1\left(\mathrm{p}=9.2 \times 10^{-6}\right)$ and $\mathrm{Cw} 2$ antigens $\left(\mathrm{p}<10^{-8}\right)$ as was expected due to the linkage disequilibrium between these antigens and B27 in the Sardinian population (Contu et al., 1992).

The comparison of gene frequencies between the group of AS patients and the 44 $\mathrm{B} 27^{+}$healthy controls was carried out with the B27 positive haplotypes on the one hand and the B27 negative haplotypes on the other (Table 3). This analysis demonstrated that the differences between the two groups concern both the alleles carried by the B27 positive haplotype (positive association for the HLA-A2, Cw2, DR2 and DQ1 antigens) and those carried by the B27 negative haplotype (positive association for HLA-Cw2 and DR2 and negative association for DR3). However, after correction for the number of comparisons made, only the differences between the frequencies of $\mathrm{A} 2$ and $\mathrm{Cw} 2$ of the $\mathrm{B} 27^{+}$haplotypes in AS patients compared to healthy controls retained significance.

The haplotypes found in patients and healthy controls are listed in Tables 4 and 5 respectively.

The B27 haplotype shows considerable homogeneity in the patients compared to the healthy controls. In fact, in the patients only 12 different B27 haplotypes out of $25(48 \%)$ are present, one haplotype is represented 12 times and only 9 haplotypes are present one single time. Instead, in the controls 35 different B 27 haplotypes out of 44 are represented (79.5\%), no haplotype is represented more than 3 times and 29 haplotypes are present 
Table 1. Significant HLA antigen differences between $\mathrm{B} 27^{+} \mathrm{AS}$ patients and random controls.

\begin{tabular}{ccccccc}
\hline \multicolumn{2}{c}{$\mathrm{AS}(\mathrm{n}=25)$} & \multicolumn{2}{c}{ Controls $\left(\mathrm{n}=220^{\circ}\right)$} & & \\
Antigens & $\mathrm{n}$ & $\%$ & $\mathrm{n}$ & $\%$ & $\mathrm{p}$ & $\mathrm{RR}$ \\
$\mathrm{A} 2$ & 20 & 80 & 117 & 53.2 & .0079 & 3.2 \\
A30 & 5 & 20 & 86 & 39.1 & .045 & 0.4 \\
Cw2 & 23 & 92 & 32 & 14.5 & $<10^{-8^{*}}$ & 54.5 \\
Cw5 & 3 & 12 & 99 & 45.0 & $.00087^{*}$ & 0.2 \\
DR2 & 23 & 92 & 83 & 37.7 & $<10^{-7 *}$ & 15.4 \\
DR3 & 5 & 20 & 108 & 49.1 & $.0043^{*}$ & 0.3 \\
DQ1 $^{\circ}$ & 23 & 92 & 86 & 53.7 & $.00012^{*}$ & 8.1 \\
DQ2 $^{\circ}$ & 6 & 24 & 90 & 56.2 & $.0023^{*}$ & 0.2 \\
\hline
\end{tabular}

only 160 controls were typed for DQ.

$* \mathrm{p}<0.05$ after correction for the antigens tested in the corresponding locus.

Table 2. Significant HLA antigen differences between $B 27^{+}$AS patients and $B 27^{+}$ healthy controls. (HC).

\begin{tabular}{|c|c|c|c|c|c|c|}
\hline \multirow[b]{2}{*}{ Antigens } & \multicolumn{2}{|c|}{ AS $(n=25)$} & \multicolumn{2}{|c|}{$\mathrm{HC}(\mathrm{n}=44)$} & \multirow[b]{2}{*}{$\mathrm{p}$} & \multirow[b]{2}{*}{$\mathrm{RR}$} \\
\hline & $\mathrm{n}$ & $\%$ & $\mathrm{n}$ & $\%$ & & \\
\hline $\mathrm{A} 2$ & 20 & 80 & 16 & 36.3 & $.00047^{*}$ & 6.4 \\
\hline Cw2 & 23 & 92 & 26 & 59.0 & $.0029 *$ & 6.5 \\
\hline DR2 & 23 & 92 & 24 & 54.5 & $.00098^{*}$ & 7.8 \\
\hline DR3 & 5 & 20 & 19 & 43.1 & .044 & 0.3 \\
\hline DQ1 & 23 & 92 & 32 & 72.7 & .050 & 3.6 \\
\hline
\end{tabular}

$* \mathrm{p}<0.05$ after correction for the antigens tested in the corresponding locus. 
Table 3. Comparison of the gene frequencies between AS patients and $\mathrm{B} 27^{+}$healthy controls (HC) calculated respectively on the HLA B27 positive and the HLA B27 negative haplotypes.

\begin{tabular}{|c|c|c|c|c|c|c|c|c|c|c|c|c|}
\hline \multicolumn{7}{|c|}{ HLA-B27 positive haplotypes } & \multicolumn{6}{|c|}{ HLA-B27 negative haplotypes } \\
\hline & \multicolumn{2}{|c|}{ AS (25) } & \multicolumn{2}{|c|}{$\mathrm{HC}(44)$} & \multirow[b]{2}{*}{$\mathrm{p}$} & \multirow[b]{2}{*}{$\mathrm{RR}$} & \multicolumn{2}{|c|}{ AS (25) } & \multicolumn{2}{|c|}{$\mathrm{HC}(44)$} & \multirow[b]{2}{*}{$\mathrm{p}$} & \multirow[b]{2}{*}{ RR } \\
\hline Antigens & $\mathrm{n}$ & $\%$ & $\mathrm{n}$ & $\%$ & & & $\mathrm{n}$ & $\%$ & $\mathrm{n}$ & $\%$ & & \\
\hline A2 & 16 & 64 & 10 & 22.7 & $.00084 *$ & 5.7 & 7 & 28 & 9 & 20.4 & ns & - \\
\hline $\mathrm{Cw} 2$ & 23 & 92 & 24 & 54.5 & $.00098 *$ & 7.8 & 6 & 24 & 2 & 4.5 & .022 & 5.6 \\
\hline DR2 & 16 & 64 & 15 & 34.1 & .015 & 3.3 & 11 & 44 & 9 & 20.4 & .037 & 2.9 \\
\hline DR3 & 2 & 8 & 3 & 6.8 & ns & - & 3 & 12 & 16 & 36.3 & .025 & 0.3 \\
\hline DQ1 & 19 & 76 & 22 & 50.0 & .030 & 3.0 & 13 & 52 & 13 & 29.5 & ns & - \\
\hline
\end{tabular}

$* \mathrm{p}<0.05$ after correction for the antigens tested in the corresponding locus.

only once (Table 6). The haplotype frequencies (Table 7) show a significant increase of the HLA-A2, Cw2, B27, DR2, DQ1 haplotype in the AS patients compared to the B27+ healthy controls $(p=0.00013)$. The differences observed between the two groups are not only significant for the entire haplotype but also for portions of it and especially for the A2, Cw2, B27 segment $(p=0.000071)$. Moreover, $92 \%$ of the AS patients carry the $\mathrm{Cw} 2-$ $\mathrm{B} 27$ haplotype against $54.5 \%$ of the $\mathrm{B} 27^{+}$healthy controls $(\mathrm{p}=0.00098)$, while the $\mathrm{Cw} 1$ B27 haplotype which is completely lacking in the patients has a frequency of $27 \%$ in the $\mathrm{B} 27^{+}$healthy control group $(\mathrm{p}=0.0023)$. It is also worth mentioning that the frequencies of the HLA-Cw1, B27, DR5, DQ3 haplotype and portions of it are significantly reduced in the patients (see Table 7). According to analysis of the haplotype frequencies carried out on the non-B27 haplotype, a significant reduction of the B18, DR3, DQ2 haplotype was observed in the AS patients ( $8 \%$ vs. $27.2 \%, \mathrm{p}=0.05)$.

Examination of the HLA Class III specificities in the families of 8 AS patients and of 3 healthy controls bearing the entire HLA-A2, Cw2, B27, DR2, DQ1 haplotype, demonstrated the presence of the BFS, C4A3, C4B1 complotype (S31) in all of the B27 haplotypes.

The segregation of the HLA-A2, Cw2, B27, DR2, DQ1 haplotype among the 12 families in which the haplotype is carried by at least one AS patient, did not vary significantly from the expected values. 
Table 4. HLA haplotypes in 25 patients affected by Ankylosing Spondylitis.

\begin{tabular}{|c|c|c|c|c|c|c|c|c|c|c|}
\hline \multirow{2}{*}{$\begin{array}{l}\text { Patient } \\
\text { P.A. }\end{array}$} & \multicolumn{5}{|c|}{ Haploptype 1} & \multicolumn{5}{|c|}{ Haplotype 2} \\
\hline & Al & $\mathrm{Cw} 3$ & B27 & DR5 & DQ3 & $\mathrm{A} 2$ & $\mathrm{Cw} 3$ & B35 & DR2 & DQ1 \\
\hline M.P. & $\mathrm{A} 2$ & $\mathrm{Cw} 2$ & B27 & DR2 & DQ1 & $\mathrm{A} 2$ & $\mathrm{Cw} 2$ & B51 & DR4 & DQ3 \\
\hline R.A. & $\mathrm{A} 2$ & $\mathrm{Cw} 2$ & B27 & DR2 & DQ1 & $\mathrm{A} 2$ & $\mathrm{Cw}-$ & B51 & DR2 & DQ1 \\
\hline L.L. & $\mathrm{A} 2$ & $\mathrm{Cw} 2$ & B27 & DR2 & DQ1 & A26 & $\mathrm{Cw} 2$ & B51 & DR2 & DQ1 \\
\hline B.P. & $\mathrm{A} 2$ & $\mathrm{Cw} 2$ & B27 & DR2 & DQ1 & $\mathrm{A} 1$ & $\mathrm{Cw} 4$ & B35 & DR7 & DQ2 \\
\hline P.G. & $\mathrm{A} 2$ & $\mathrm{Cw} 2$ & B27 & DR2 & DQ1 & A 30 & Cw5 & B 18 & DR3 & DQ2 \\
\hline P.E. & $\mathrm{A} 2$ & $\mathrm{Cw} 2$ & B27 & DR2 & DQ1 & A 30 & Cw5 & B 18 & DR3 & DQ2 \\
\hline F.I. & $\mathrm{A} 2$ & $\mathrm{Cw} 2$ & B27 & DR2 & DQ1 & A- & $\mathrm{Cw} 7$ & B 17 & DR2 & DQ1 \\
\hline O.F. & $\mathrm{A} 2$ & $\mathrm{Cw} 2$ & B27 & DR2 & DQ1 & Al1 & $\mathrm{Cw} 2$ & B44 & DR5 & DQ3 \\
\hline P.R. & $\mathrm{A} 2$ & $\mathrm{Cw} 2$ & B27 & DR2 & DQ1 & A30 & Cw6 & B37 & DR5 & DQ3 \\
\hline M.S. & $\mathrm{A} 2$ & $\mathrm{Cw} 2$ & B27 & DR2 & DQ1 & A26 & $\mathrm{Cw}-$ & B 14 & DR 1 & DQ1 \\
\hline F.G. & A 2 & Cw2 & B27 & DR2 & DQ1 & A- & $\mathrm{Cw} 2$ & B40 & DR5 & DQ3 \\
\hline S.B. & $\mathrm{A} 2$ & $\mathrm{Cw} 2$ & B27 & DR2 & DQ1 & $\mathrm{A} 1$ & $\mathrm{Cw} 7$ & B49 & DR4 & DQ3 \\
\hline D.S. & $\mathrm{A} 2$ & Cw2 & B27 & DR3 & DQ2 & A30 & Cw5 & B 18 & DR5 & DQ3 \\
\hline A.S. & $\mathrm{A} 2$ & Cw2 & B27 & DR4 & DQ3 & A33 & $\mathrm{Cw}-$ & B 14 & DR2 & DQ1 \\
\hline C.G. & $\mathrm{A} 2$ & $\mathrm{Cw} 2$ & B27 & DR4 & DQ3 & A 2 & $\mathrm{Cw} 2$ & B51 & DR4 & DQ3 \\
\hline P.M. & $\mathrm{A} 2$ & Cw2 & B27 & DR 10 & DQI & $\mathrm{A} 1$ & $\mathrm{Cw} 2$ & B40 & DR2 & DQ1 \\
\hline P.G. & A11 & Cw2 & B27 & DR5 & DQ3 & A32 & $\mathrm{Cw} 7$ & B 18 & DR2 & DQ I \\
\hline P.F. & A 23 & Cw2 & B27 & DR2 & DQ1 & $\mathrm{A} 2$ & $\mathrm{Cw}-$ & B 18 & DR2 & DQ1 \\
\hline C.R. & A23 & $\mathrm{Cw} 2$ & B27 & DR2 & DQ1 & A24 & $\mathrm{Cw} 7$ & B8 & DR3 & DQ2 \\
\hline M.M. & A24 & $\mathrm{Cw} 2$ & B27 & DR2 & DQ1 & A11 & $\mathrm{Cw} 4$ & B35 & DR4 & DQ3 \\
\hline P.A. & A 24 & $\mathrm{Cw} 2$ & B27 & DR 10 & DQ1 & $\mathrm{A} 2$ & $\mathrm{Cw}-$ & B 16 & DR2 & DQ 1 \\
\hline C.R. & A 30 & $\mathrm{Cw} 2$ & B27 & DR2 & DQ1 & A- & $\mathrm{Cw}-$ & B 14 & DR 1 & DQ1 \\
\hline O.G. & A32 & $\mathrm{Cw}-$ & B27 & DR 1 & DQ1 & $\mathrm{A} 1$ & $\mathrm{Cw} 4$ & B35 & DR2 & DQ1 \\
\hline V.L. & A- & Cw2 & B27 & DR3 & DQ2 & $\mathrm{A} 2$ & $\mathrm{Cw}-$ & B 17 & DR2 & DQ1 \\
\hline
\end{tabular}

\section{DISCUSSION}

Our study shows the existence of several significant variations of the HLA antigen distribution in AS patients when compared to random controls and to $\mathrm{B} 27^{+}$healthy controls. In particular, the frequencies of A2, Cw2 and DR2 are significantly increased in patients. It must be noted that the frequency of A2 in the group of 44 healthy $\mathrm{B} 27^{+}$ controls is much lower than that observed in the group of 220 random controls, which could be due to the small size of the sampling. However, when the haplotypes are examined separately (Table 3 ), the distribution of $\mathrm{A} 2$ on the $\mathrm{B} 27^{+}$and $\mathrm{B} 27^{-}$haplotypes in the group of healthy controls is similar, while in patients the frequency of A2 is 
Table 5. HLA haplotypes in 45 heálthy B27 positive controls.

\begin{tabular}{|c|c|c|c|c|c|c|c|c|c|c|}
\hline \multirow{2}{*}{$\frac{\text { Subjects }}{\text { M.D. }}$} & \multicolumn{5}{|c|}{ Haplotype 1} & \multicolumn{5}{|c|}{ Haplotype 2} \\
\hline & Al & $\mathrm{Cw} 2$ & B27 & DR2 & DQ1 & A.33 & $\mathrm{CW}-$ & B 14 & DRI & DQ1 \\
\hline S.O. & Al & $\mathrm{Cw}-$ & B27 & DR2 & DQ1 & A- & $\mathrm{Cw}-$ & B44 & DR- & DQ- \\
\hline C.N. & A2 & $\mathrm{Cw} 2$ & B27 & DR2 & DQ1 & A9 & $\mathrm{Cw}-$ & B58 & DR5 & DQ3 \\
\hline G.P. & A2 & $\mathrm{Cw} 2$ & B27 & DR2 & DQ1 & A33 & $\mathrm{Cw} 3$ & B 17 & DR3 & DQ2 \\
\hline G.L. & A2 & $\mathrm{Cw} 2$ & B27 & DR2 & DQ1 & A24 & Cw6 & B 14 & DRI & DQ1 \\
\hline T.A. & A2 & $\mathrm{Cw} 1$ & B27 & DR3 & DQ2 & A2 & $\mathrm{Cw} 2$ & B58 & DR2 & DQ1 \\
\hline S.A. & A2 & $\mathrm{Cw} 2$ & B27 & DR3 & DQ2 & A2 & $\mathrm{Cw}-$ & B57 & DR2 & DQ1 \\
\hline V.M. & A2 & Cw2 & B27 & DR4 & DQ3 & A 24 & Cw4 & B35 & DR3 & DQ2 \\
\hline Z.V. & A2 & $\mathrm{Cw} 1$ & B27 & DR5 & DQ3 & A- & $\mathrm{Cw}-$ & B 17 & DR2 & DQ1 \\
\hline T.M. & A2 & $\mathrm{Cw} 1$ & B27 & DR5 & DQ3 & A2 & $\mathrm{Cw}-$ & B17 & DR2 & DQ1 \\
\hline R.B. & A2 & Cw2 & B27 & DR5 & DQ3 & A 30 & Cw5 & B18 & DR3 & DQ2 \\
\hline P.E. & A2 & Cw2 & B27 & DR- & DQ- & Al & $\mathrm{Cw}-$ & B8 & DR3 & DQ2 \\
\hline M.S. & A 3 & $\mathrm{Cw}-$ & B27 & DR3 & DQ2 & A2 & $\mathrm{Cw}-$ & B 18 & DR5 & DQ3 \\
\hline C.R. & A9 & $\mathrm{Cw}_{2}$ & B27 & DRI & DQ1 & A30 & Cw5 & B 18 & DR3 & DQ2 \\
\hline R.R. & A9 & $\mathrm{CW}-$ & B27 & DRI & DQI & A 11 & $\mathrm{Cw} 4$ & B35 & DR2 & DQ1 \\
\hline P.A. & A9 & $\mathrm{Cw} 2$ & B27 & DR2 & DQI & A26 & $\mathrm{Cw}-$ & B 18 & DR5 & DQ3 \\
\hline L.A. & A9 & $\mathrm{Cw}_{2}$ & B27 & DR2 & DQI & $\mathrm{A} 2$ & Cw5 & B18 & DR3 & DQ2 \\
\hline P.R. & A9 & $\mathrm{Cw}_{2}$ & B27 & DR2 & DQI & A2 & $\mathrm{Cw}-$ & B44 & DR4 & DQ3 \\
\hline B.E. & All & $\mathrm{Cw}_{2}$ & B27 & DR1 & DQI & A 30 & Cw5 & B18 & DR3 & DQ2 \\
\hline M.M. & All & $\mathrm{Cw} 2$ & B27 & DR1 & DQI & A28 & $\mathrm{Cwl}$ & B55 & DR- & DQ- \\
\hline S.D. & All & $\mathrm{Cw}_{2}$ & B27 & DR- & DQ- & A26 & $\mathrm{Cw}-$ & B58 & DR5 & DQ3 \\
\hline M.R. & All & $\mathrm{Cw} 2$ & B27 & DR5 & DQ3 & A28 & $\mathrm{Cwl}$ & B55 & DR2 & DQ1 \\
\hline A.M. & A24 & $\mathrm{Cw} 2$ & B27 & DR- & DQ- & A30 & $\mathrm{Cw}-$ & B 18 & DR2 & DQ1 \\
\hline P.A. & A26 & $\mathrm{Cwl}$ & B27 & DR5 & DQ2 & A 30 & Cw5 & B18 & DR3 & DQ2 \\
\hline F.L. & A 30 & $\mathrm{Cw}_{2}$ & B27 & DR 1 & DQ1 & A 30 & Cw5 & B18 & DR3 & DQ2 \\
\hline C.C. & A 30 & Cwl & B27 & DR2 & DQ1 & A 32 & $\mathrm{Cw} 4$ & B35 & DR5 & DQ3 \\
\hline D.G. & A30 & $\mathrm{Cw}_{2}$ & B27 & DR2 & DQ1 & A3 & $\mathrm{Cw}-$ & B- & DR3 & DQ2 \\
\hline L.R. & A 30 & $\mathrm{Cw}_{2}$ & B27 & DR2 & DQ1 & A 30 & Cw5 & B18 & DR3 & DQ2 \\
\hline V.A. & A 30 & $\mathrm{Cw}-$ & B27 & DR5 & DQ2 & A 30 & Cw5 & B18 & DR3 & DQ2 \\
\hline P.S. & A 30 & Cw2 & B27 & DR- & DQ- & A9 & $\mathrm{Cw}-$ & B 12 & DR4 & DQ3 \\
\hline P.L. & A 32 & $\mathrm{Cw}-$ & B27 & DR 1 & DQ1 & A- & $\mathrm{Cw}-$ & B14 & DR7 & DQ2 \\
\hline U.T. & A 32 & $\mathrm{Cw} 2$ & B27 & DR2 & DQ1 & A 30 & Cw5 & B18 & DR3 & DQ2 \\
\hline A.B. & A 32 & $\mathrm{Cw} /$ & B27 & DR2 & DQI & Al & $\mathrm{Cw}-$ & B52 & DR- & DQ- \\
\hline P.F. & A 32 & $\mathrm{Cwl}$ & B27 & DR5 & DQ3 & A2 & $\mathrm{Cw}-$ & B18 & DR3 & DQ2 \\
\hline P.G. & A 32 & $\mathrm{Cw} 1$ & B27 & DR5 & DQ3 & A2 & $\mathrm{Cw}-$ & B18 & DR3 & DQ2 \\
\hline V.A. & A 32 & Cwl & B27 & DR5 & DQ3 & A2 & $\mathrm{Cw}-$ & B8 & DR6 & DQ1 \\
\hline D.L. & A.32 & $\mathrm{Cw}-$ & B27 & DR5 & DQ3 & A11 & $\mathrm{Cw} 7$ & B7 & DR2 & DQ1 \\
\hline L.A. & A 32 & $\mathrm{Cw} I$ & B27 & DR- & DQ- & A- & $\mathrm{Cw}-$ & B39 & DR2 & DQ1 \\
\hline D.E. & A- & Cw2 & B27 & DR 1 & DQ1 & A 30 & Cw5 & B18 & DR3 & DQ2 \\
\hline C.W. & A- & Cw2 & B27 & DR2 & DQ1 & A 32 & $\mathrm{Cw}-$ & B44 & DR- & DQ- \\
\hline T.S. & A- & $\mathrm{Cw}-$ & B27 & DR2 & DQ1 & A 32 & Cw- & B7 & DR4 & DQ3 \\
\hline S.S. & A- & $\mathrm{Cw} 1$ & B27 & DR5 & DQ3 & A- & $\mathrm{Cw}-$ & B- & DR- & DQ- \\
\hline C.G. & A- & $\mathrm{Cw}-$ & B27 & DR5 & DQ3 & $\mathrm{A} 30$ & Cw5 & B18 & DR1 & DQ1 \\
\hline D.G. & A- & $\mathrm{Cw} 1$ & B27 & DR- & DQ- & A30 & $\mathrm{Cw} 2$ & B44 & DR5 & DQ3 \\
\hline N.A.* & A3 & $\mathrm{Cw} 2$ & B27 & DR2 & DQ1 & A23 & Cw5 & B27 & DR3 & DQ2 \\
\hline
\end{tabular}

* One proband, homozygous for the B27 allele, was excluded from the statistical analysis. 
Table 6. Number of exemplars of each different B27 haplotype in AS patients and in healthy controls (HC).

\begin{tabular}{|c|c|c|c|c|c|c|}
\hline \multirow{3}{*}{$\begin{array}{c}\text { Exemplars of each } \\
\text { haplotype } \\
\mathrm{n}^{\circ}\end{array}$} & \multicolumn{3}{|c|}{ AS $(n=25)$} & \multicolumn{3}{|c|}{$\mathrm{HC}(\mathrm{n}=44)$} \\
\hline & $\begin{array}{c}\text { Different } \\
\text { haplotypes }\end{array}$ & & otypes & $\begin{array}{c}\text { Different } \\
\text { haplotypes }\end{array}$ & Total & lotypes \\
\hline & $\mathrm{n}^{\circ}$ & $\mathrm{n}^{\circ}$ & $\%$ & $\mathrm{n}^{\circ}$ & $\mathrm{n}^{\circ}$ & $\%$ \\
\hline 1 & 9 & 9 & 36 & 29 & 29 & 65.9 \\
\hline 2 & 2 & 4 & 16 & 3 & 6 & 13.6 \\
\hline 3 & 0 & 0 & - & 3 & 9 & 20.4 \\
\hline 12 & 1 & 12 & 48 & 0 & 0 & - \\
\hline Total & 12 & 25 & & 35 & 44 & \\
\hline
\end{tabular}

Table 7. Frequencies of the A2 Cw2 B27 DR2 DQ1 haplotype, parts of it, and of other relevant haplotypes in AS patients and in healthy B27 positive controls.

\begin{tabular}{lcccccc}
\hline & \multicolumn{2}{c}{ AS $(\mathrm{n}=25)$} & \multicolumn{2}{c}{ Controls $(\mathrm{n}=44)$} & & \\
Haplotypes & $\mathrm{n}$ & $\%$ & $\mathrm{n}$ & $\%$ & $\mathrm{p}$ & $\mathrm{RR}$ \\
\hline A2 Cw2 B27 DR2 DQ1 & 12 & 48 & 3 & 6.8 & .00013 & 10.9 \\
Cw2 B27 DR2 DQ1 & 16 & 64 & 11 & 25.0 & .0016 & 5.1 \\
B27 DR2 DQ1 & 16 & 64 & 15 & 34.0 & .015 & 3.3 \\
A2 Cw2 B27 & 16 & 64 & 7 & 15.9 & .000071 & 8.6 \\
Cw2 B27 & 23 & 92 & 24 & 54.5 & .00098 & 7.8 \\
\hline Cw1 B27 DR5 DQ3 & - & - & 7 & 15.9 & .035 & 0.1 \\
B27 DR5 DQ3 & 2 & 8 & 12 & 27.2 & .050 & 0.3 \\
Cw1 B27 & - & - & 12 & 27.2 & .0023 & 0.05 \\
\hline
\end{tabular}


significantly higher on the $\mathrm{B} 27^{+}$haplotype than on the $\mathrm{B} 27^{-}$haplotype $(\mathrm{p}=0.011)$. This confirms the existence of an association between A2 and AS in our case report. Previous studies have suggested that HLA antigens other than B27 are capable of influencing the susceptibility to AS (Troug et al., 1975; McDaniel et al., 1987; Robinson et al., 1989) or the onset and evolution of some of its complications (Sanmartì et al., 1987; Aaron et al., 1985, Miehle et al., 1985).

However, in these studies the non-B27 HLA antigens associated with the disease were different from those observed in our patients. It is possible that these differences were connected with the different ethnic origin of the patients. The Sardinian population, for various reasons (isolation, random genetic drift, selection, high degree of inbreeding), presents peculiar genetic characteristics which distinguish it from other Caucasoid populations (Piazza et al., 1985; Contu et al., 1992; Contu et al., 1989). In some cases these differences also concern the association of HLA with disease (La Nasa et al., 1991; Carcassi et al., 1991). A recent study (Contu et al., 1992) has revealed the presence in the Sardinian population of a haplotype (A2, Cw2, B27, DR2) in strong linkage disequilibrium (LD) $\left(\Delta=17.3, \chi^{2}=86.2\right)$. The component alleles of this haplotype are the same as those which present significantly increased frequencies in our AS patients. It is therefore likely that the increased frequency of the antigens in the AS patients is at least partly due to the LD existing in the Sardinian population between these antigens and B27. However, the frequency of this haplotype among the AS patients is much higher than that observed in the $\mathrm{B} 27^{+}$healthy controls $(48 \%$ vs. $6.8 \%$, $\mathrm{p}=0.00013$ ). This seems to exclude the hypothesis that A2, Cw2 and DR2 are associated with AS simply because of the effect of their linkage disequilibrium with B27, and instead suggests the involvement of the entire A2, Cw2, B27, DR2 haplotype, a part of it, or of single component alleles. Alternatively, it could also be that the B27 haplotype of the patients is different from that of the healthy controls.

However, preliminary data on Class III alleles demonstrated that the BfS, C4A3, $\mathrm{C} 4 \mathrm{~B} 1$ complotype is constantly present in this haplotype in both AS patients and healthy controls. Of course, investigation must be extended to other families to define this aspect. It is interesting to note that in a previous study (Lochead et al., 1983) the S31 complotype was also found associated with the Cw2-B27 haplotype in AS patients and in controls, while the S42 complotype was associated to the Cw1-B27 haplotype.

The different behaviour of the $\mathrm{Cw} 2-\mathrm{B} 27$ and $\mathrm{Cw} 1-\mathrm{B} 27$ haplotypes observed in our AS patients and $\mathrm{B} 27^{+}$controls seems to indicate the involvement of the $\mathrm{Cw} 2$ antigen in susceptibility to AS (see Table 7). Both the $\mathrm{Cw} 1$ and the $\mathrm{Cw} 2$ alleles are in strong LD with B27 in Caucasoid populations including the Sardinian population (Contu et al. 1992). However, while the $\mathrm{Cw} 2-\mathrm{B} 27$ and $\mathrm{Cw} 1-\mathrm{B} 27$ haplotypes are respectively represented in $54.5 \%$ and $27.2 \%$ of the healthy control group, the $\mathrm{Cw} 2-\mathrm{B} 27$ haplotype is represented in $92 \%$ of the patients and none of them have the Cw1-B27 haplotype. Comparative family studies on B27 heterozygous AS patients and healthy controls in other populations (Troug et al., 1975; Lochead et al., 1983) have not demonstrated any differences in the distribution of the $\mathrm{Cw} 1-\mathrm{B} 27$ and $\mathrm{Cw} 2-\mathrm{B} 27$ haplotypes among the two groups. The discordance with our data is likely to be of an ethnic nature. If in the Sardinian population AS affects almost exclusively individuals carrying the Cw2-B27 and not the $\mathrm{Cw} 1-\mathrm{B} 27$ haplotype while in other populations it does not show any preferences for one of the two haplotypes, it would be possible to presume the existence of a major "AS gene" distinct from B27, in a locus very close to the B locus and in strong 
LD with B27. In the Sardinian population this "AS gene" would then have to be present practically exclusively on the Cw2-B27 haplotype and not on the $\mathrm{Cw} 1-\mathrm{B} 27$ haplotype, while in other populations it would have a normal distribution on both haplotypes. Until now, there is no other evidence to support this hypothesis and data in literature concur in maintaining that B27 is the main, if not only, AS gene. The possibility that the Cw2 and/or B27 alleles in LD in AS patients are different from those in LD in the healthy controls must also be considered. On this point the data available regarding the Sardinian population are inadequate, but studies carried out in other populations have not demonstrated any significant difference in the distribution of the B27 subtypes in AS patients and in controls (Breur-Vriesendorp et al., 1987; Kellner and Yu, 1992) and seem to indicate that the reason for susceptibility to AS conferred by the B27 antigen is more likely to lie in structural motifs common to the different B27 subtypes, than in epitopes which differentiate one subtype from the other. In at least four of the seven B27 subtypes to date described (B27*05, B27*02, B27*04 and B27*06) an association with AS has been reported (Khan, 1992). Among Caucasoid populations, B27*05 represents $85-90 \%$ of all the B27 subtypes, B27*02 represents $10 \%$ and $\mathrm{B} 27 * 01$ is extremely rare while the other variants seem to be completely lacking (Kellner and Yu, 1992). However, studies on the distribution of B27 variants in respect of AS in the different populations are fragmentary and insufficient to clarify this important aspect. A theoretical interpretation of the data observed is that not all B27 variants confer equal susceptibility to AS and that in the Sardinian population Cw 1 is in LD with a B27 variant not susceptible to AS and that $\mathrm{Cw} 2$ is in $\mathrm{LD}$ with a B27 variant susceptible to AS. In other populations $\mathrm{Cw} 1$ and $\mathrm{Cw} 2$ could both be associated with $\mathrm{B} 27$ variants susceptible to AS.

As far as the behaviour of the DR2 antigen is concerned, a possible involvement in AS susceptibility seems to be suggested by the fact that the DR2 frequency in our patients is significantly higher than in the $\mathrm{B} 27^{+}$healthy controls on both the $\mathrm{B} 27$ positive and $\mathrm{B} 27$ negative haplotypes. Therefore for DR2 also the possibility must be considered that the subtype associated with AS may be different from the one present in the $\mathrm{B} 27^{+}$healthy controls.

An investigation which is currently in progress in our laboratory seems to demonstrate that the DR2 allele carried by the A2 Cw2 B27 haplotype is in fact the DRB $1 * 1601$ subtype in both the patients and in the healthy controls. What is more, previous studies have demonstrated that in the Sardinian population the DR2 allele is mostly represented by the DRB $1 * 1601$ variant (in strong LD with DQB $1 * 0502$ ) and is associated with some organ specific auto immune diseases (La Nasa et al., 1991; Carcassi et al., 1991).

If $\mathrm{AS}$ is the consequence of a cytotoxic reaction of the $\mathrm{T} \mathrm{CD}^{+}$lymphocytes (CTL) against target cells presenting a particular arthritogenic peptide on the B27 molecule, as strongly suggested by recent data (Kellner and Yu, 1992; Khan, 1992; Benjamin and Parham, 1992) then it would logically have to be admitted that the activation of selfreactive CTL necessarily involves cytokines produced by $\mathrm{CD}^{+}{ }^{+} \mathrm{T}$ helper lymphocytes which in turn have been activated by exogenous peptides presented by class II HLA molecules on APC cells. The question is then why have there been so few reports of an association of class II HLA molecules with AS (Troug et al., 1975; Sanmartì et al., 1987; Aaron et al., 1985; Miehle et al., 1985)? The reasons for this may be as follows:

1- Until now, only a few studies have been carried out on the HLA class II molecules in AS; 
2- No one class II molecule is specifically involved in the pathogenesis of AS but many different DR, DQ and DP molecules are capable of binding the responsible peptides and of activating the T CD4 lymphocytes in order to transmit a second signal to the CTL.

3- the DR2 alleles which prevail in the large majority of Caucasoid populations are DRB $1 * 1501$ and DRB $1 * 1502$ while in the Sardinian population, the predominant variant is DRB $1 * 1601$. If this variant is more strongly involved in AS than the other DR molecules than the reason why the AS-DR2 association emerged in our study and not in others would be quite clear.

The most common extended haplotype in the Sardinian population is A30, Cw5, B18, DR3, DQ2 with a frequency of $12-15 \%$ and very high $L D$ values $\left(\Delta=1425.3, \chi^{2}=12086\right)$ (Contu et al., 1992; Contu et al., 1989). This haplotype only appears twice (8\%) in the AS patients showing a lower frequency than in the $\mathrm{B} 27^{+}$controls where it tends to have a higher frequency than in the general population. In fact, in the $\mathrm{B} 27^{+}$controls it is present 9 times $(20.4 \%)$ and 12 times $(27.2 \%)$ if only the B 18, DR3, DQ2 segment is considered. The difference between the two groups is significant $(p=0.05)$ and may therefore indicate a protective effect of the DR3 allele or of the entire extended haplotype but is more probably secondary to the strong increase of the DR2 allele frequency in AS patients.

In conclusion, the data reported reveal a significantly increased frequency of the HLA-A2 Cw2 B27 DR2 haplotype in our AS patients. This increase does not depend on the LD existing in the Sardinian population between the B27 allele and the other component alleles of this haplotype nor does it seem to concern a different haplotype with some allelic variations in the AS patients compared to the $\mathrm{B} 27^{+}$healthy controls. The complotype (S31) and the DR2 allele (DRB 1*1601) are the same in both AS patients and B27 healthy controls. Instead as shown by our data, it is likely that the increased frequency of the entire haplotype in the AS patients is secondary to an independent association of the $\mathrm{Cw} 2$ antigens and DR 16 with AS in the $\mathrm{B} 27^{+}$patients. The possibility that different B27 variants conferring different susceptibility to AS distinguish the $\mathrm{Cw} 2$ B27 from the Cw1-B27 haplotype in the Sardinian population, cannot be excluded.

ACKNOWLEDGEMENTS

We wish to thank Anna Koopmans for the preparation of the manuscript. This work was supported by grants from the Assessorato Igiene e Sanità, Regione Autonoma della Sardegna (Grant $n^{0}$ PR N39773/112) and from the Italian National Research Council (CNR) (Grant no 91.01160.PF70).

\section{REFERENCES}

Aaron, S., Miller, M.L., Howard, J.H., Fraser, P.A., Jackson, J.M., Larson, M.G., Glass, D.N. (1985). Complementation with HLA-A and D locus alleles in ankylosing spondylitis with peripheral arthritis. J. Rheumatol., 12, 553-557.

Alper, C.A., Boenish, T. Watson, L. (1972). Genetic polymorphism in human glycine-rich betaglycoprotein. J. Exp. Med., 135, 68-80. 
Awdeh, A.L., Alper, C.A. (1980). Inherited structural polymorphism of the fourth component of human complement. Proc. Natl. Acad. Sci., USA, 77, 3576-3580.

Benjamin, R., Parham, P. (1992). HLA-B27 and disease: a consequence of inadvertent antigen presentation?. Rheum. Dis. Clin. North Am., 18, 11-21.

Breur-Vriesendorp, B.S., Dekker-Saeys, A.J., Ivanyi, P. (1987). Distribution of HLA-B27 subtypes in patients with ankylosing spondylitis: the disease is associated with a common determinant of the various B27 molecules. Ann. Rheum. Dis., 46, 353-356.

Calin, A. (1982). Ankylosing Spondylitis. In: Kelley, W.N., Harris, E.D. Jr., Ruddy, S., Sledge, C.B (Eds.), Textbook of Rheumatology. Philadelphia, W.B. Saunders C., 1982.

Calin, A., Elswood, J. (1989). Relative role of genetic and environmental factors in disease expression: sib pair analysis in ankylosing spondylitis. Arthritis Rheum., 32, 77-81.

Carcassi, C., Trucco, G., Trucco, M., Contu, L. (1991). A new extended HLA-DR2 haplotype is involved in Insulin Dependent Diabetes Mellitus susceptibility. Hum. Immunol., 31, 159-164.

Contu, L., Arras, M., Carcassi, C., La Nasa, G., Mulargia, M. (1992). HLA structure of the Sardinian population: a haplotype study of 551 families. Tissue Antigens, 4, 165-175.

Contu, L., Capelli, P., Sale, S. (1977). HLA B27 and ankylosing spondylitis: a population and family study in Sardinia. J. Rheumatol., suppl. 3, 18-23.

Contu, L., Carcassi, C., Dausset, J. (1989). The Sardinian "HLA - A30, B18, DR3, DQw2 haplotype constantly lacks the 21-OHA and C4B genes. Is it an ancestral haplotype without duplication? Immunogenetics, 30, 13-17.

Demazière, A., Ferec, C., Fauquert, P., Youinou, P., Le Goff, P. (1990). A Pvu II restriction polymorphism of class I genes in ankylosing spondylitis. Absence of relation with the 9.2 band. Rev. Rheum Mal. Osteoartic, 57, 53-57.

Derhaag, P.J.F.M. (1990). Genetical factors other than HLA-B27 in "HLA-B27 associated diseases". Scand. J. Rheumatol., suppl., 87, 122-126.

Durand, J.P., Taurog, J.D. (1988). Association between Ankylosing Spondylitis and $9.2 \mathrm{~kb}$ Pvu II class I HLA DNA restriction fragment: A reassessment. J. Rheumatol., 15, 1119-1122.

Haldane, J.B.S. (1955). The estimation and significance of the logarithm of a ratio of frequencies. Ann. Hum. Genet., 20, 309-311.

Kellner, H., Yu, D. (1992). The pathogenetic aspects of spondyloarthropathies from the point of view of HLA-B27. Rheumatol. Int., 12, 121-127.

Khan, M.A. (1992). An overview of clinical spectrum and heterogeneity of spondyloarthropathies. Rheum. Dis. Clin. North Am., 18, 1-10.

Khan, M.A.., Kushner, I., Braun, W.E. (1980). Genetic heterogeneity in primary ankylosing spondylitis. J. Rheumatol. 7, 383-386.

La Nasa, G., Martino, E., Carcassi, C., Mulargia, M., Floris, L., Vacca, A., Baldini, G., Orrù, S., Ledda, A., Grasso, L., Velluzzi, F., Contu, L. (1991). Serological and molecular studies of HLA in Sardinian patients with Graves' disease. Dis. Markers, 9, 307-312.

Lochead, J.A., Chalmers, I.A., Marshall, W.H., Larsen, B., Skanes, V.M., Payne, R.H., Barnard, J.M. (1983). HLA-B27 Haplotypes in family studies of Ankylosing Spondylitis. Arthritis Rheum., 26, 1012-1016.

McDaniel, D.O., Acton, R.T., Barger, B.O., Koopman, W.J., Reveill, J.D. (1987). Association of a 9.2-Kilobase Pvu II class I major histocompatibility complex restriction fragment length polymorphism with ankylosing spondylitis. Arthritis Rheum., 30, 894-900.

Miehle, W., Schattenkirchner, M., Albert, D., Bunge, M.(1985). HLA-DR4 in ankylosing spondylitis with different patterns of joint involvement. Ann. Rheum. Dis., 44, 39-44.

Møller, P., Vinje, O., Kass, E., Berg, K. (1982). The distribution of clinical findings in Bechterew's syndrome (ankylosing spondylitis) suggest distinct genetic subgroups. Clin. Gen., 22, 151-159.

Piazza, A., Mayr, W.R., Contu, L., Amoroso, A., Borelli, I., Curtoni, E.S., Marcello, C., Moroni, A., Olivetti, E., Richiardi, P., Ceppellini, R. (1985). Genetic and population structure of four Sardinian villages. Ann. Hum. Genet., 49, 47-63. 
Robinson W.P., Van Der Linden, S.M., Khan, M.A., Rentsch, H., Cats, A., Russel, A., Thomson, G. (1989). HLA-Bw60 increases susceptibility to Ankylosing Spondylitis in HLA-B27 ${ }^{+}$ patients. Arthritis Rheum., 32, 1135-1141.

Sanmartì, R., Ercilla, M.G., Brancòs, M.A., Cid, M.C., Collado, A., Rotés-Querol, J. (1987). HLA class II antigens (Dr, DQ loci) and peripheral arthritis in ankylosing spondylitis. Ann. Rheum. Dis., 46, 497-500.

Tiwari, J.L., Terasaki, P.I. (1985). Rheumatology and joint diseases. In: HLA and Disease Association. New York, Springer Verlag, 1985.

Tiwari, J.L., Terasaki, P.I. (1985). The data and statistical analysis. In: HLA and disease associations. Springer Verlag. New York, 1985.

Troug, P. Steiger, U., Contu. L., Galfre, G., Trucco, M., Bernoco, D., Bernoco, M., Birgen, I., Dolivo, P., Ceppellini, R. (1975). Ankylosing Spondylitis (AS): a population and family study using HLA Serology and MLR. In: F. Kissmeyer-Nielsen (Ed.), Histocompatibility Testing. Copenhagen, Munksgaard. 1975.

Woodrow, J.C. (1985). Genetic aspects of the spondyloarthropathies. Clin. Rheum. Dis., 11, 124. 


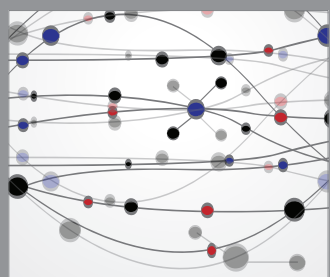

The Scientific World Journal
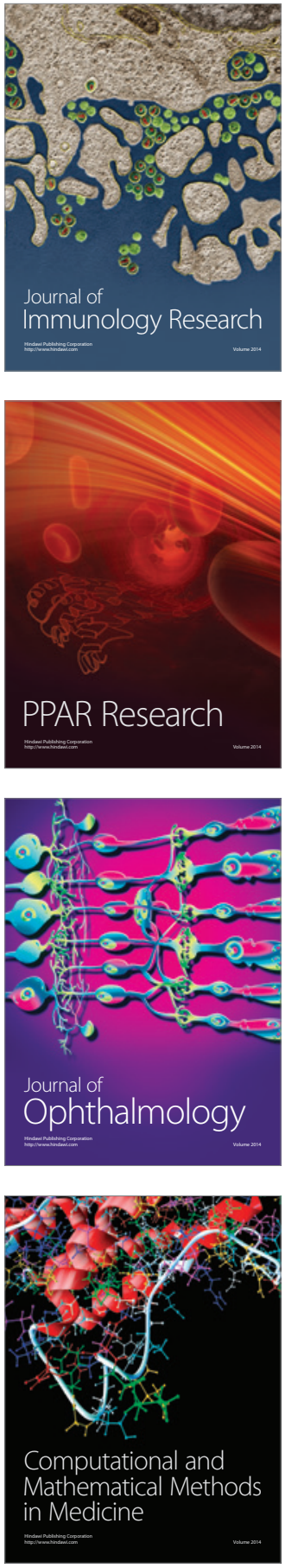

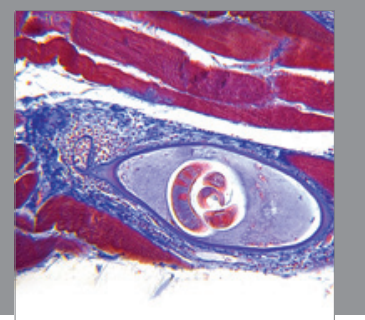

Gastroenterology

Research and Practice
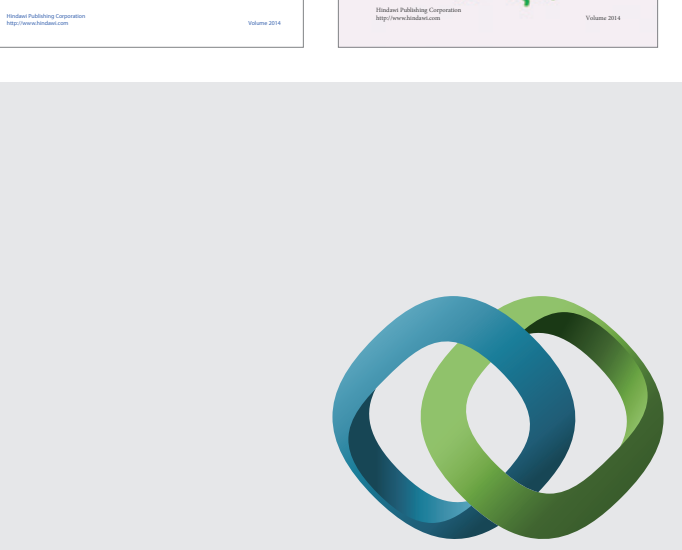

\section{Hindawi}

Submit your manuscripts at

http://www.hindawi.com
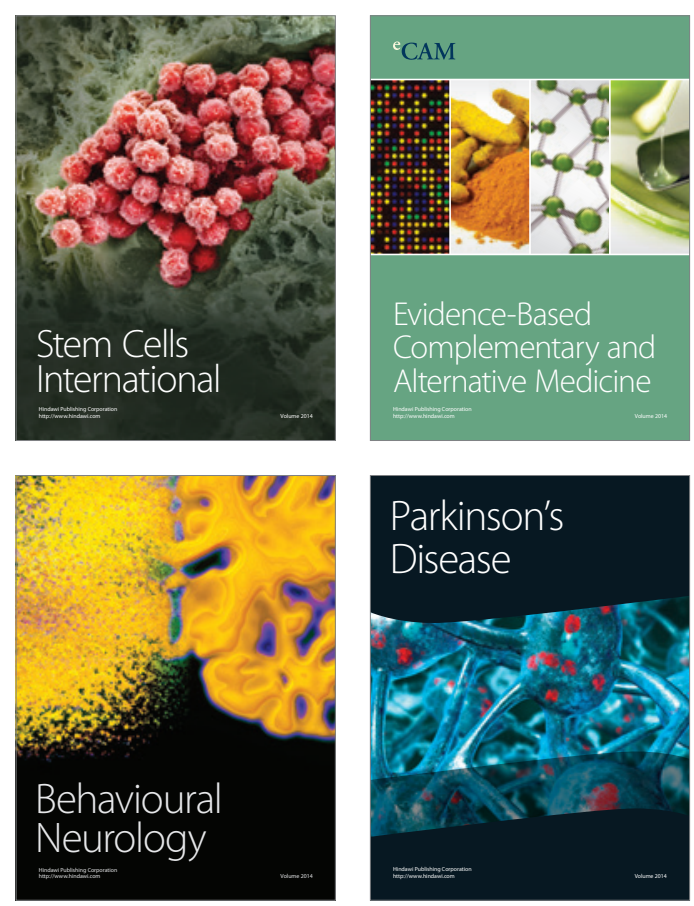

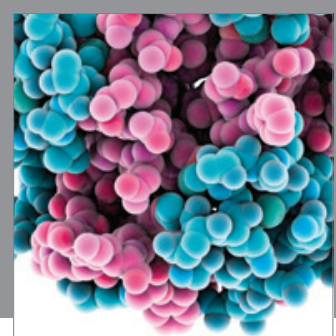

Journal of
Diabetes Research

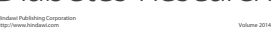

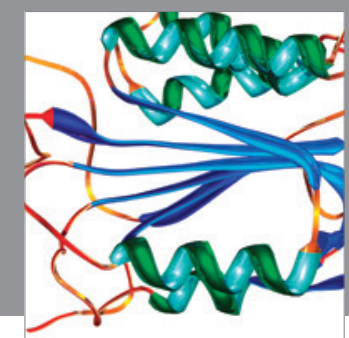

Disease Markers
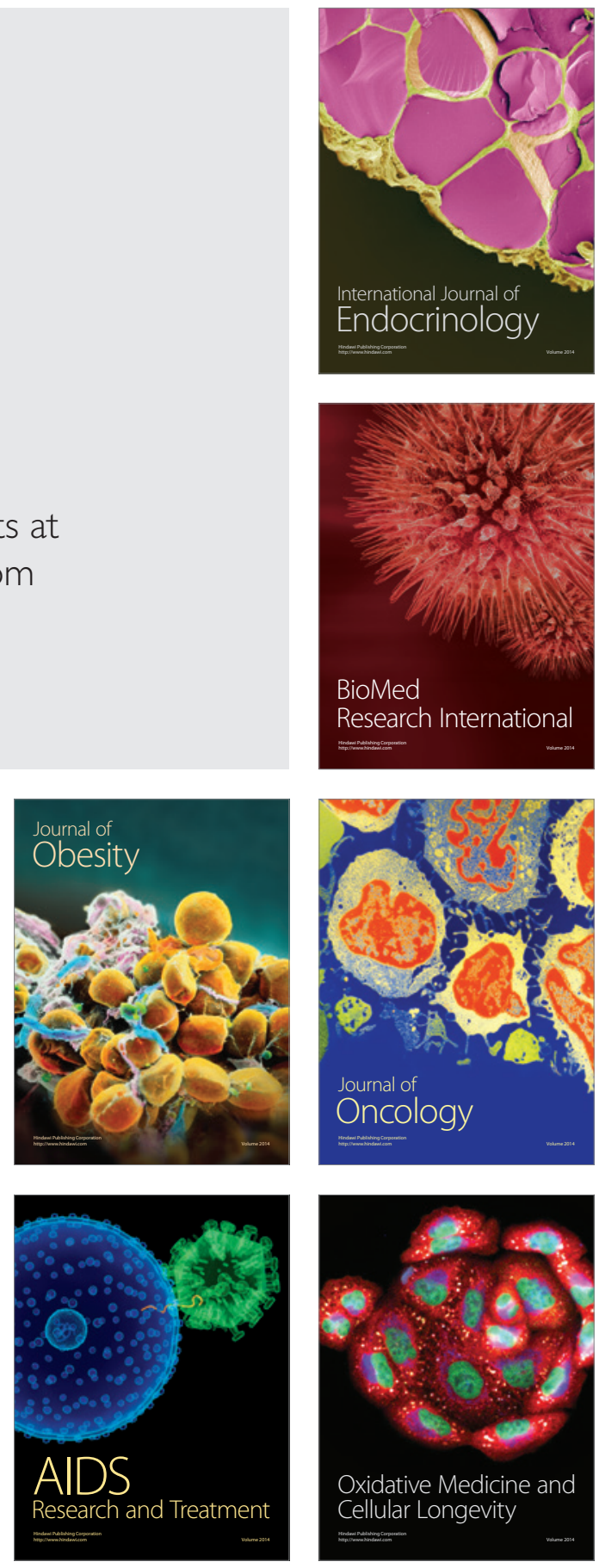